\title{
Mathematical model for carbon monoxide oxidation: influence of diffusion effects
}

\author{
Ryzha I., Gaiduchok O. \\ Lviv Polytechnic National University \\ 12 S. Bandera Str., 79013, Lviv, Ukraine
}

(Received 10 March 2019; Revised 19 May 2019; Accepted 2 June 2019)

\begin{abstract}
A two-dimensional mathematical model for carbon monoxide oxidation on the platinum catalyst surface is investigated according to the Langmuir-Hinshelwood mechanism. This model takes into account the influence of diffusion effects on the course of reaction-diffusion processes. It is established that the diffusion of adsorbed oxygen atoms can be neglected, and the structural changes of the catalyst surface have a significant influence on the character of oscillatory mode of reaction.
\end{abstract}

Keywords: reaction of catalytic oxidation, reaction-diffusion model, mathematical modeling of reaction-diffusion processes.

2000 MSC: 37E99, 82D99, 82C21

UDC: $519.876 .5,66.011$

DOI: $10.23939 / \mathrm{mmc} 2019.01 .129$

\section{Introduction}

Industrial significant reactions of chemical synthesis are reactions of heterogeneous catalysis, that is, reactions that take place on the catalyst surface or in the near-surface layer. In this case, the occurring reaction-diffusion processes are systems far from the state of thermodynamic equilibrium and arise under conditions of particles and energy exchange with an environment. Such systems demonstrate a number of specific physical and chemical phenomena (oscillatory behavior in chemical reactions, the propagation of chemical waves of adsorbed particles, etc.) characteristic only for processes of heterogeneous catalysis. This means that, on the one hand, the properties of the catalyst surface significantly influence the flow of reaction-diffusion processes, and on the other hand, the presence of the near-surface layer substantially changes both the structure of the catalyst surface and the course of reaction. Such features of heterogeneous catalysis complicate conducting experimental studies of the catalyst surface structure and kinetics of reaction-diffusion processes that occur on it. Under these conditions, there is a need to construct and investigate mathematical models of catalytic systems with a clearly defined structure of the catalyst surface and understandable at the atomic-molecular level mechanisms of reaction-diffusion processes that occur on it.

Historically, the first mathematical models which managed to explain the oscillatory mode of a simple reaction of heterogeneous catalysis - the reaction of carbon monoxide $(\mathrm{CO})$ oxidation on the platinum (Pt) catalyst surface were models proposed by K. Krischer, M. Eiswirth, G. Ertl (the KEE model) [1] and R. M. Ziff, E. Gulari, Y. Barshad (the ZGB model) [2]. Further improvements of these models known from literature [3-8] unfortunately did not allow to describe all experimentally observed phenomena characteristic of reaction-diffusion processes on the catalyst surface. Therefore, the development of approaches to mathematical modeling of the influence of a number of factors (the surface reconstruction stimulated by interaction between molecules adsorbed on a surface and substrate atoms, the topology of a surface, the near-surface layer structure, etc.) on the flow of reaction-diffusion processes is an actual and important task.

The purpose of present paper is to construct and study mathematical model for reaction-diffusion processes of $\mathrm{CO}$ oxidation on the Pt-catalyst surface and to establish regularities of the influence of the surface structure and diffusion effects on the flow of these processes. 


\section{Description of mathematical model}

We consider a model for reaction-diffusion processes of CO oxidation on Pt-catalyst surface on the basis of generalized KEE model [9]. It takes into account the peculiarities of the Langmuir-Hinshelwood mechanism $[10,11]$ for a chemical reaction, the nanostructure reconstruction of $\operatorname{Pt}(110)$ surface during CO oxidation [12-14] and the diffusion processes of adsorbed CO molecules and oxygen (O) atoms along the catalytic surface [15]. The catalytic surface is assumed to be flat with a given Cartesian coordinate system $X O Y$. The coordinate axes $O X$ and $O Y$ are directed for $\mathrm{Pt}(110)$ along perpendicular [11̄0] and [001] directions, respectively. The catalyst temperature $T$ is constant and acts as an external parameter of a model. The system of kinetic equations that describe temporal changes of adsorbed $\mathrm{CO}(u)$ and $\mathrm{O}(v)$ surface coverages, as well as the fraction of catalyst surface in the nonreconstructed $(1 \times 1)$ structure $(w)$ and the degree of catalyst surface faceting $(z)$, has the form:

$$
\begin{aligned}
& \frac{\partial u}{\partial t}=p_{\mathrm{CO}} \kappa_{u} s_{u}\left[1-\left(\frac{u}{u_{s}}\right)^{3}\right]-k_{1} u v-k_{2} u+D_{u_{1}} \frac{\partial^{2} u}{\partial x^{2}}+D_{u_{2}} \frac{\partial^{2} u}{\partial y^{2}}, \\
& \frac{\partial v}{\partial t}=p_{\mathrm{O}_{2}} \kappa_{v}\left[w s_{v_{1}}+(1-w) s_{v_{2}}+z s_{v_{3}}\right]\left(1-\frac{u}{u_{s}}-\frac{v}{v_{s}}\right)^{2}-k_{1} u v+D_{v_{1}} \frac{\partial^{2} v}{\partial x^{2}}+D_{v_{2}} \frac{\partial^{2} v}{\partial y^{2}}, \\
& \frac{\partial w}{\partial t}=k_{3}(f(u)-w)+D_{w_{1}} \frac{\partial^{2} w}{\partial x^{2}}+D_{w_{2}} \frac{\partial^{2} w}{\partial y^{2}}, \\
& \frac{\partial z}{\partial t}=k_{4} u v w(1-z)-k_{5} z(1-u) .
\end{aligned}
$$

Here $p_{\mathrm{CO}}, p_{\mathrm{O}_{2}}$ are the partial pressures of $\mathrm{CO}$ and $\mathrm{O}_{2}$, respectively; $\kappa_{u}, \kappa_{v}$ are the impingement rates; $s_{u}, s_{v_{1,2,3}}$ are the sticking coefficients; $u_{s}, v_{s}$ are the saturation coverages; $D_{u_{1,2}}, D_{v_{1,2}}$ are the diffusion coefficients of adsorbed $\mathrm{CO}$ and $\mathrm{O}$ along $O X$ and $O Y$ axes, respectively.

Since $w$ describes the probability for a catalyst surface to be in the nonreconstructured $1 \times 1$ structure, the evolution equation for $w$ (3) has a structure similar to the Fokker-Planck-Kolmogorov equation [16], that is, contains diffusion components with corresponding $D_{w_{1,2}}$ coefficients in both $O X$ and $O Y$ directions. A non-decreasing smooth function $f(u)$, that takes on values in interval [0;1], is modeled similarly to [17] as follows:

$$
f(u)=\left[1+\exp \left(\frac{u_{0}-\frac{u}{u_{s}}}{\delta u}\right)\right]^{-1},
$$

where $u_{0}, \delta u$ are the parameters of structural transition $1 \times 1 \leftrightarrows 1 \times 2$ on $\operatorname{Pt}(110)$ surface.

The coefficient $k_{4}$, which characterizes the rate of facet formation, is constant and does not depend on the catalyst temperature $T$. While the rates of reaction $\left(k_{1}\right)$, desorption of CO molecules from the catalyst surface $\left(k_{2}\right)$, structural transition $\left(k_{3}\right)$ and thermal annealing $\left(k_{5}\right)$ are temperature dependent and are determined by the Arrhenius equations [18]:

$$
k_{i}=k_{i}(T)=k_{i}^{0} \exp \left(-\frac{E_{i}}{R T}\right)
$$

where $k_{i}^{0}$ are the temperature independent coefficients; $E_{i}$ are the activation energies; $R$ is the universal gas constant [19].

In general, the diffusion coefficient $D$ depends on many parameters: temperature, concentration (in our case adsorbate surface coverage) and other physical properties of the surface [15]. The temperature dependence of diffusion coefficient can be described by the Arrhenius equation:

$$
D=D(T)=D_{0} \exp \left(-\frac{E_{a}}{R T}\right),
$$


where $D_{0}$ is the temperature independent coefficient; $E_{a}$ is the activation energy. In adsorbate systems the activation energy depends on the surface coverage of adsorbed substance and reflects the particleparticle interaction and the peculiarities of particle binding on the particular adsorption sites [15]. For reaction of carbon monoxide catalytic oxidation on $\mathrm{Pt}(110)$, the diffusion coefficient of adsorbed $\mathrm{CO}$ molecule does not have a pronounced dependence on the surface coverage $u$, but substantially depends on the structure of the catalyst surface: the CO diffusion can be up to 10 times faster along the [110] direction, than along the perpendicular direction [001] [20]. The adsorbed oxygen in turn diffuses practically only parallel to the [110] direction and significantly depends on $\mathrm{O}$ surface coverage: at small values of $v(0 \leqslant v<0.2)$ the diffusion coefficient of $\mathrm{O}$ is higher by one order of magnitude than at high coverage $(0.2 \leqslant v<0.7)[15]$.

We introduce dimensionless variables:

$$
\begin{gathered}
U=\frac{u}{u_{s}}, \quad V=\frac{v}{v_{s}}, \\
\tilde{x}=\frac{x}{l_{0}}, \quad \tilde{y}=\frac{y}{l_{0}}, \quad \tilde{t}=\frac{t}{t_{c}},
\end{gathered}
$$

where

$$
t_{c}=\frac{v_{s}}{p_{\mathrm{co}} \kappa_{u} s_{u}}
$$

in which equations (1)-(4) can be rewritten in dimensionless form:

$$
\begin{aligned}
& \frac{\partial U}{\partial \tilde{t}}=\frac{v_{s}}{u_{s}}\left(1-U^{3}\right)-\tilde{k}_{1} v_{s} U V-\tilde{k}_{2} U+\tilde{D}_{u}\left(\frac{\partial^{2} U}{\partial \tilde{x}^{2}}+d_{u} \frac{\partial^{2} U}{\partial \tilde{y}^{2}}\right), \\
& \frac{\partial V}{\partial \tilde{t}}=\tilde{p}_{\mathrm{O}_{2}}\left[w s_{v_{1}}+(1-w) s_{v_{2}}+z s_{v_{3}}\right](1-U-V)^{2}-k_{1} u_{s} U V+\tilde{D}_{v}\left(\frac{\partial^{2} V}{\partial \tilde{x}^{2}}+d_{v} \frac{\partial^{2} V}{\partial \tilde{y}^{2}}\right), \\
& \frac{\partial w}{\partial \tilde{t}}=\tilde{k}_{3}\left[1+\exp \left(\frac{u_{0}-U}{\delta u}\right)\right]^{-1}-\tilde{k}_{3} w+\tilde{D}_{w}\left(\frac{\partial^{2} w}{\partial \tilde{x}^{2}}+d_{w} \frac{\partial^{2} w}{\partial \tilde{y}^{2}}\right), \\
& \frac{\partial z}{\partial \tilde{t}}=\tilde{k}_{4} u_{s} v_{s} U V w(1-z)-\tilde{k}_{5} z\left(1-u_{s} U\right) .
\end{aligned}
$$

Here

$$
\begin{gathered}
\tilde{p}_{\mathrm{O}_{2}}=\frac{p_{\mathrm{O}_{2}} \kappa_{v} t_{c}}{v_{s}}, \quad \tilde{k}_{i}=k_{i} t_{c}, \quad i=\overline{1,5} \\
\tilde{D}_{j}=\frac{D_{j 1} t_{c}}{l_{0}^{2}}, \quad d_{j}=\frac{D_{j 2}}{D_{j 1}}, \quad j=\{u, v, w\} .
\end{gathered}
$$

\section{Numerical analysis}

First when investigating the system (7)-(10) we consider the case where a diffusion term is absent in equation (9) for the change of $w$ the fraction of surface in the nonreconstructed $(1 \times 1)$ structure, that is $\tilde{D}_{w} \equiv 0$. The values of parameters present in model are given in Table $1[1,15,17]$. The results of the corresponding numerical analysis of system (7)-(10) are presented in Fig. 1, 2.

It is seen from graphs that at partial pressures $p_{\mathrm{CO}}=2.65 \times 10^{-5}$ Torr, $p_{\mathrm{O}_{2}}=6.4 \times 10^{-5}$ Torr and temperature $T=540 \mathrm{~K}$ the mixed mode oscillations (the fine structure of oscillatory reaction) arise in a system. Taking into account the influence of the catalyst surface nano-inhomogeneities (starting with an adsorbate-induced structural reconstruction and ending with the formation of new crystal planes faceting) on the process of $\mathrm{CO}$ oxidation substantially affects the character of reaction oscillatory mode. The appearance of a fine structure (an alternation of oscillations of different large and small amplitudes) can be explained with a change in the number of adsorption centers on the catalyst surface 
Table 1. Parameters of mathematical model.

\begin{tabular}{|l|l|l|ll|}
\hline CO & $\kappa_{u}$ & Impingement rate & $4.2 \times 10^{5} 1 / \mathrm{s}$ Torr & \\
& $s_{u}$ & Sticking coefficient & 1 & \\
& $u_{s}$ & Saturation coverage & 1 & \\
& $D_{u_{1}}$ & Diffusion coefficient & $1.2 \times 10^{-7} \mathrm{~cm}^{2} / \mathrm{s}$ & \\
& $d_{u}$ & Model parameter of diffusion & 0.1 & \\
\hline $\mathrm{O}_{2}$ & $\kappa_{v}$ & Impingement rate & $7.8 \times 10^{5} 1 / \mathrm{s}$ Torr & \\
& $s_{v}$ & Sticking coefficient & $(1 \times 1): s_{v_{1}}=0.6$ & $(1 \times 2): s_{v_{2}}=0,4$ \\
& & & Facets: $s_{v_{3}}=0.2$ & \\
& $v_{s}$ & Saturation coverage & 0.8 & \\
& $D_{v_{1}}$ Diffusion coefficient & $0 \leqslant v<0.2:$ & $D_{v}^{0}=2 \times 10^{3 \pm 1} \mathrm{~cm}^{2} / \mathrm{s}$ \\
& & & & $E_{a}=30 \pm 4 \mathrm{kcal} / \mathrm{mol}$ \\
& & & $0.2 \leqslant v<0.7:$ & $D_{v}^{0}=2 \times 10^{5 \pm 0.5} \mathrm{~cm} / \mathrm{s}$ \\
& & & $0.1 ; 0.01$ & $E_{a}=40 \pm 2 \mathrm{kcal} / \mathrm{mol}$ \\
& $d_{v}$ & Model parameter of diffusion & $k_{1}^{0}=3 \times 10^{6} 1 / \mathrm{s} ;$ & $E_{1}=10 \mathrm{kcal} / \mathrm{mol}$ \\
& $k_{1}$ & Reaction & $k_{2}^{0}=2 \times 10^{16} 1 / \mathrm{s} ;$ & $E_{2}=38 \mathrm{kcal} / \mathrm{mol}$ \\
& $k_{2}$ & Desorption of CO & $k_{3}^{0}=2 \times 10^{-2} 1 / \mathrm{s} ;$ & $E_{3}=7 \mathrm{kcal} / \mathrm{mol}$ \\
& $k_{3}$ & Structural transition & $0.031 / \mathrm{s}$ & \\
& $k_{4}$ & Facet formation & $k_{5}^{0}=2.65 \times 10^{5} 1 / \mathrm{s} ;$ & $E_{5}=20 \mathrm{kcal} / \mathrm{mol}$ \\
& $k_{5}$ & Thermal annealing & $540 \mathrm{~K}$ & \\
\hline Other & $T$ & Temperature & $0.001987 \mathrm{kcal} /(\mathrm{mol} \cdot \mathrm{K})$ & \\
& $R$ & Gas constant & $u_{0}=0.35 ; \delta u=0.05$ & \\
& & Parameters of structural transition &
\end{tabular}
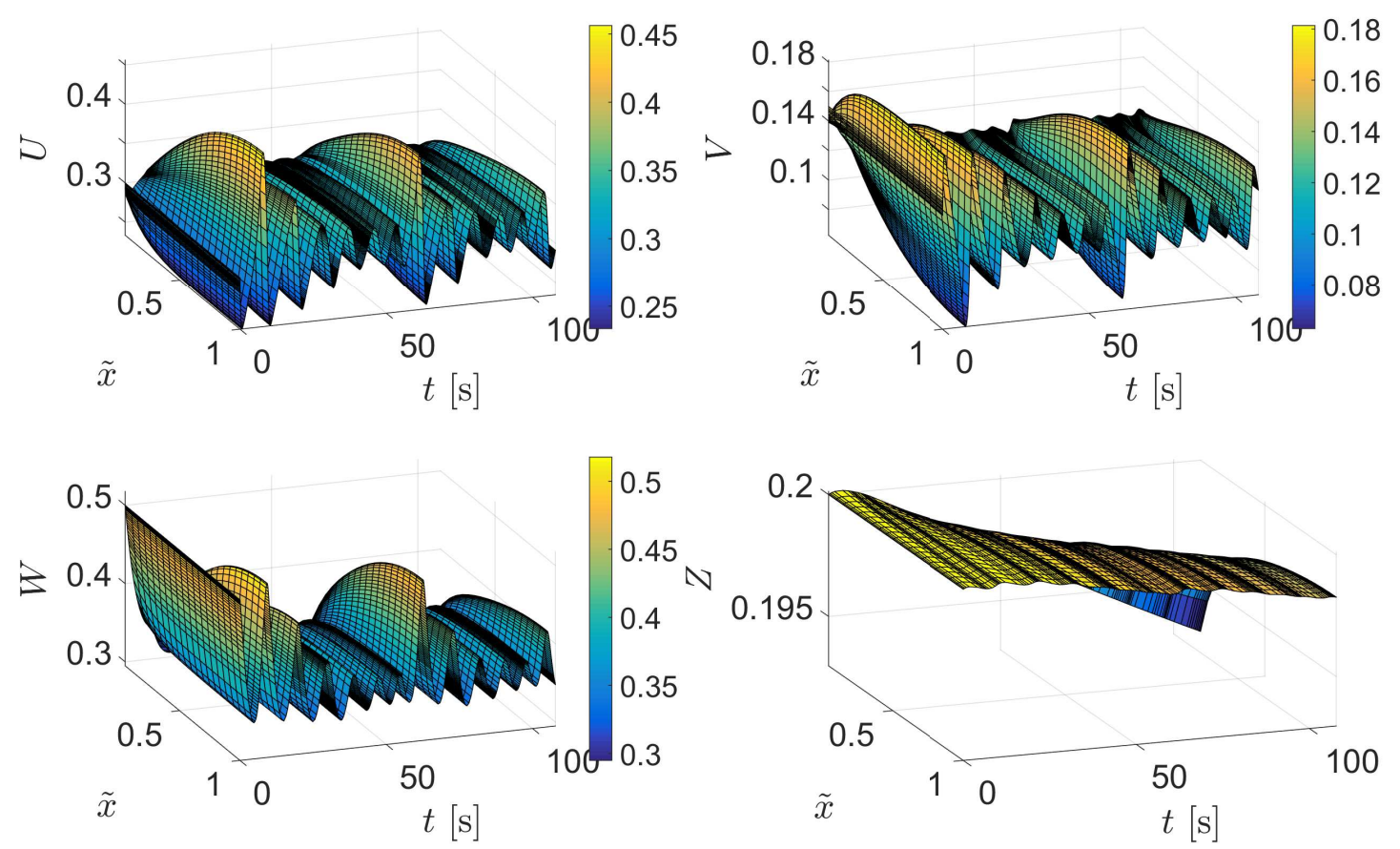

Fig. 1. Dependency of $\mathrm{CO} U(\tilde{x}, \tilde{y}, t)$ and $\mathrm{O} V(\tilde{x}, \tilde{y}, t)$ surface coverages, fraction of surface in the nonreconstructed $(1 \times 1)$ structure $w(\tilde{x}, \tilde{y}, t)$ and degree of faceting $z(\tilde{x}, \tilde{y}, t)$ for $\tilde{D}_{w} \equiv 0, l_{0}=10^{-3} \mathrm{~cm}, T=540 \mathrm{~K}$, $p_{\mathrm{CO}}=2.65 \times 10^{-5}$ Torr, $p_{\mathrm{O}_{2}}=6.4 \times 10^{-5}$ Torr, $\tilde{y}=0.1$ and diffusion model parameter: $d_{v}=0.1$. 

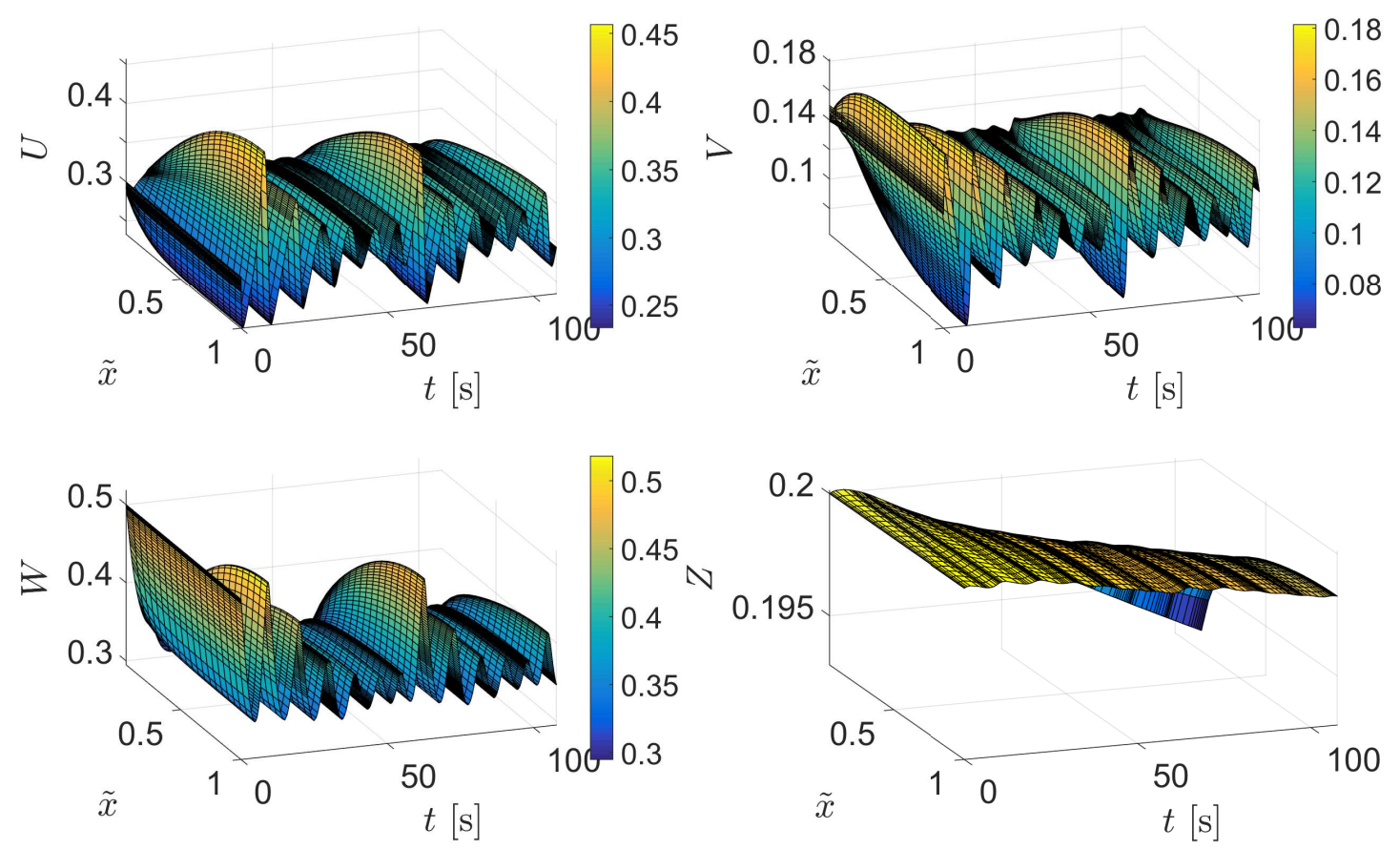

Fig. 2. Dependency of CO $U(\tilde{x}, \tilde{y}, t)$ and $\mathrm{O} V(\tilde{x}, \tilde{y}, t)$ surface coverages, fraction of surface in the nonreconstructed $(1 \times 1)$ structure $w(\tilde{x}, \tilde{y}, t)$ and degree of faceting $z(\tilde{x}, \tilde{y}, t)$ for $\tilde{D}_{w} \equiv 0, l_{0}=10^{-3} \mathrm{~cm}, T=540 \mathrm{~K}$, $p_{\mathrm{CO}}=2.65 \times 10^{-5}$ Torr, $p_{\mathrm{O}_{2}}=6.4 \times 10^{-5}$ Torr, $\tilde{y}=0.1$ and diffusion model parameter $d_{v}=0.01$.

and an increase of oxygen sticking coefficient on a faceted surface. At the same time the character of oscillatory mode does not change for the different values of diffusion model parameter of adsorbed oxygen atoms, for example $d_{v}=0.1$ (see Fig. 1 ) and $d_{v}=0.01$ (see Fig. 2), and, moreover, it coincides with the corresponding results of numerical calculations for the case when adsorbed oxygen is considered immobile $\left(\tilde{D}_{v} \equiv 0\right)[21]$. This is due to the fact that a larger coefficient of O diffusion $D_{v_{1}}$ along $O X$ axis is still 100 times smaller than the corresponding diffusion coefficient of adsorbed CO $D_{u_{1}}$ and 10 times smaller than the diffusion coefficient $D_{u_{2}}$ in the direction of $O Y$. Such a slow diffusion prevents the adsorbed atom of oxygen from moving along the catalyst surface. It will rather react with $\mathrm{CO}$ molecule, which was adsorbed on a neighbor active site or has moved there due to diffusion.

Fig. 3 shows the results of numerical analysis of model (7)-(10) for the case when the diffusion components are taken into account in equation (9) for the change of $w$ the fraction of surface in the nonreconstructed $(1 \times 1)$ structure. We see that at the same external parameters $\left(p_{\mathrm{CO}}=2.65 \times 10^{-5}\right.$ Torr, $p_{\mathrm{O}_{2}}=6.4 \times 10^{-5}$ Torr, $T=540 \mathrm{~K}$ ) as previous ones the oscillatory behavior of the system changes dramatically. For $\tilde{D}_{w}=0.01$, that is $\frac{D_{u_{1}}}{D_{w_{1}}} \sim 10$ (see Fig. $3 a$ ) the oscillatory mode does not have a pronounced character, and for $\tilde{D}_{w}=0.1$, that is $\frac{D_{u_{1}}}{D_{w_{1}}} \sim 1$ (see Fig. $3 b$ ) there are no oscillations at all and the system is in a state of high reactivity, when adsorbed $\mathrm{CO}$ molecules and $\mathrm{O}$ atoms are located on the catalyst surface.

The change in oscillatory character of $\mathrm{CO}$ oxidation with a change of the value of the fraction of surface in the nonreconstructed $(1 \times 1)$ structure is due to the fact that as a result of rapid $w$ diffusion $\left(D_{w_{1}} \sim D_{u_{1}}\right)$ there is disappearing delay in transition of the catalytic surface from active to inactive structure in relation to the change of CO surface coverage, which is observed when the diffusion effects are neglected. Consequently the catalyst surface will reconstruct faster to the $(1 \times 1)$ structure on which the sticking probability of oxygen is higher than on the reconstructed $(1 \times 2)$ structure. Therefore, in the process of competitive adsorption the catalytic surface will be able to adsorb more oxygen that will enter into a chemical reaction with adsorbed $\mathrm{CO}$ and the system will be in a state of high reactivity. 

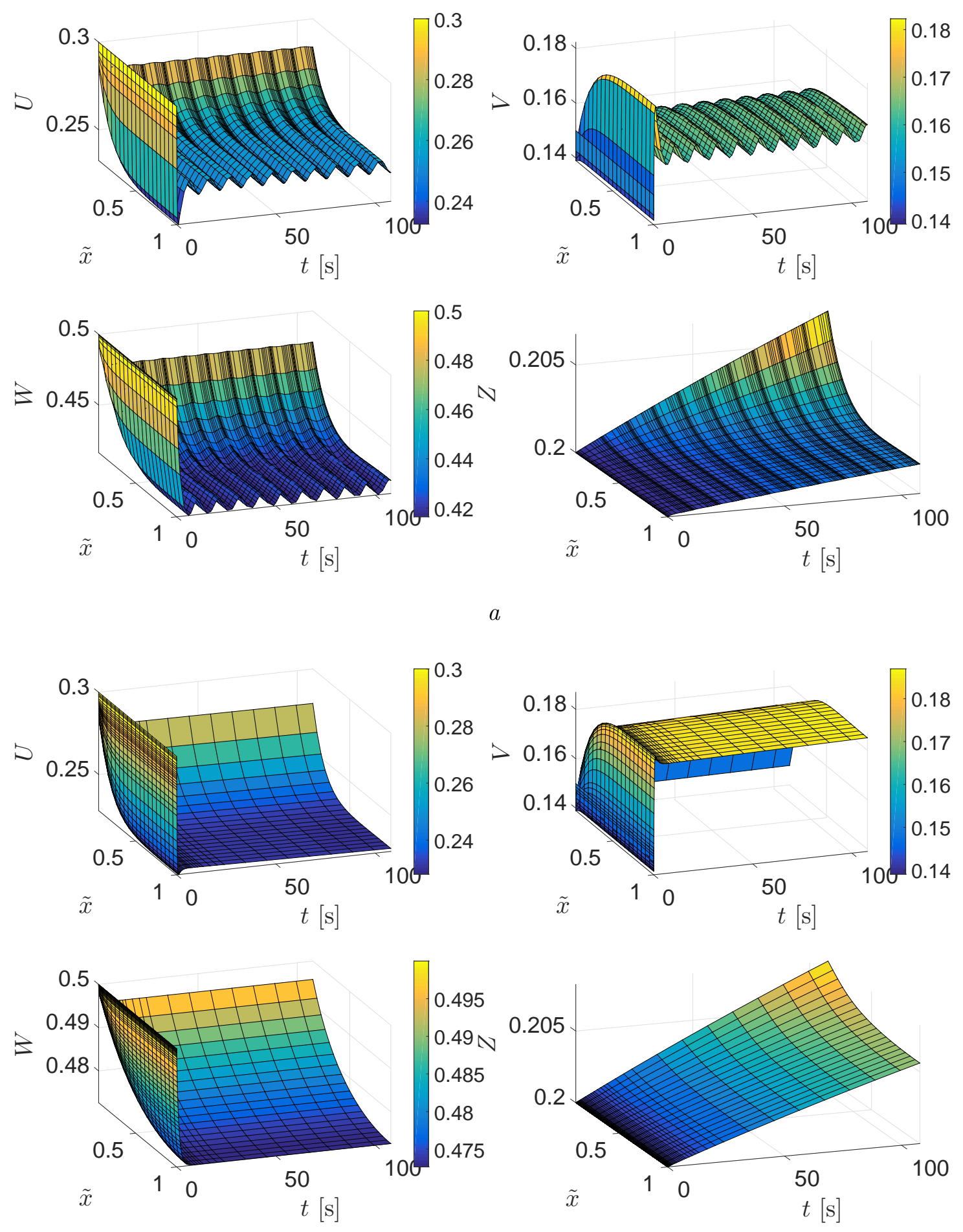

$b$

Fig. 3. Dependency of $\mathrm{CO} U(\tilde{x}, \tilde{y}, t)$ and $\mathrm{O} V(\tilde{x}, \tilde{y}, t)$ surface coverages, fraction of surface in the nonreconstructed $(1 \times 1)$ structure $w(\tilde{x}, \tilde{y}, t)$ and degree of faceting $z(\tilde{x}, \tilde{y}, t)$ for $d_{w}=1, l_{0}=10^{-3} \mathrm{~cm}, T=540 \mathrm{~K}$, $p_{\mathrm{CO}}=2.65 \times 10^{-5}$ Torr, $p_{\mathrm{O}_{2}}=6.4 \times 10^{-5}$ Torr, $\tilde{y}=0.1$ and certain value of $w$ diffusion coefficient: $a-\tilde{D}_{w}=0.01$; $b-\tilde{D}_{w}=0.1$. 


\section{Conclusions}

In present paper the two-dimensional mathematical model for carbon monoxide oxidation on the $\mathrm{Pt}$ catalyst surface is developed and investigated according to the Langmuir-Hinshelwood mechanism. This model takes into account the Pt(110) surface nano-inhomogeneities (starting with an adsorbateinduced structural reconstruction and ending with the formation of new crystal planes - faceting) and the diffusion processes of adsorbed CO molecules and oxygen atoms along the catalyst surface. It is shown that the diffusion of adsorbed oxygen atoms can be neglected, and the structural changes of the $\mathrm{Pt}(110)$ surface have a significant influence on the character of oscillatory mode of reaction.

[1] Krischer K., Eiswirth M., ErtlG. Oscillatory CO oxidation on Pt(110): Modeling of temporal selforganization. J. Chem. Phys. 96 (12), 9161-9172 (1992).

[2] Ziff R. M., Gulari E., Barshad Y. Kinetic phase transitions in an irreversible surface-reaction model. Phys. Rev. Lett. 56 (24), 2553-2556 (1986).

[3] Bär M., Zülicke C., Eiswirth M., Ertl G. Theoretical modeling of spatiotemporal self-organization in a surface catalyzed reaction exhibiting bistable kinetics. J. Chem. Phys. 96 (11), 8595-8604 (1992).

[4] Bzovska I. S., Mryglod I. M. Surface Patterns in Catalytic Carbon Monoxide Oxidation Reaction. Ukr. J. Phys. 61 (2), 134-142 (2016).

[5] Qiao L., Li X., Kevrekidis I. G., Punckt C., Rotermund H. H. Enhancement of surface activity in CO oxidation on $\mathrm{Pt}(110)$ through spatiotemporal laser actuation. Phys. Rev. E. 77, 036214 (2008).

[6] Cisternas Y., Holmes P., Kevrekidis I. G., Li X. CO oxidation on thin Pt crystals: Temperature slaving and the derivation of lumped models. J. Chem. Phys. 118 (7), 3312-3328 (2003).

[7] Bär M., Gottschalk N., Eiswirth M., Ertl G. Spiral waves in a surfacereaction: model calculations. J. Chem. Phys. 100 (2), 1202-1214 (1994).

[8] Pavlenko N. CO-activator model for reconstructing Pt(100) surfaces: Local microstructures and chemical turbulence. Phys. Rev. E. 77, 026203-1-10 (2008).

[9] Kostrobij P., Ryzha I., Markovych B. Mathematical model of carbon monoxide oxidation: influence of the catalyst surface structure. Mathematical Modeling and Computing. 5 (2), 158-168 (2018).

[10] Langmuir I. The mechanism of the catalytic action of platinum in the reactions $2 \mathrm{CO}+\mathrm{O}_{2}=2 \mathrm{CO}_{2}$ and $2 \mathrm{H}_{2}+\mathrm{O}_{2}=2 \mathrm{H}_{2} \mathrm{O}$. Trans. Faraday Soc. 17, 621-654 (1922).

[11] Imbihl R., Ertl G. Oscillatory Kinetics in Heterogeneous Catalysis. Chem. Rev. 95 (3), 697-733 (1995).

[12] Gritsch T., Coulman D., Behm R. J., Ertl G. Mechanism of the CO-induced $(1 \times 2)-(1 \times 1)$ structural transformation of $\operatorname{Pt}(110)$. Phys. Rev. Lett. 63 (10), 1086-1089 (1989).

[13] Ladas S., Imbihl R., Ertl G. Microfacetting of a Pt(110) surface during catalytic CO oxidation. Surf. Science. 197 (1-2), 153-182 (1988).

[14] Ladas S., Imbihl R., Ertl G. Kinetic oscillations and facetting during the catalytic CO oxidation on Pt(110). Surf. Science. 198 (1-2), 42-68 (1988).

[15] von Oertzen A., Rotermund H. H., Nettesheim S. Diffusion of carbon monoxide and oxygen on Pt(110): experiments performed with the PEEM. Surf. Science. 311 (3), 322-330 (1994).

[16] van Kampen N. G. Stohasticheskie processy v fizike i himii. Vysshaja shkola, Moskva (1990), (in Russian).

[17] Bzovska I. S., Mryglod I. M. Chemical oscillations in catalytic CO oxidation reaction. Condens. Matter Phys. 13 (3), 34801:1-5 (2010).

[18] Connors K. A. Chemical Kinetics: The Study of Reaction Rates in Solution. VCH Publishers, New York (1990).

[19] Kuchling H. Physik Nachschlagebücher für Grundlagenfächer. VEB Fachbuchverlag, Leipzig (1973), (in German).

[20] Patchett A. J., Meissen F., Engel W., Bradshaw A. M., Imbihl R. The anatomy of reaction diffusion fronts in the catalytic oxidation of carbon monoxide on platinum (110). Surf. Science. 454 (1), 341-346 (2000).

[21] Kostrobij P., Ryzha I. Two-dimensional mathematical model for carbon monoxide oxidation process on the platinum catalyst surface. Chem. Chem. Technol. 12 (4), 451-455 (2018). 


\title{
Математична модель оксидації чадного газу: вплив дифузійних ефектів
}

\author{
Рижа I., Гайдучок О. \\ Національний університет "Львівсъка політехніка" \\ вул. С. Бандери, 12, Львів, 79013, Україна
}

Досліджено двовимірну математичну модель окиснення монооксиду вуглецю на поверхні платинового каталізатора згідно з механізмом Ленгмюра-Гіншелвуда, яка враховує вплив дифузійних ефектів на перебіг реакційно-дифузійних процесів. Встановлено, що адсорбовані атоми кисню можна вважати нерухомими, а структурні зміни поверхні каталізатора істотно впливають на характер коливного режиму реакції.

Ключові слова: каталітична реакиія окиснення, реакиійно-дифузійна модель, математичне моделювання реакиійно-дифузійних процесів.

2000 MSC: 37E99, 82D99, 82C21

Удк: $519.876 .5,66.011$ 